\title{
Novel method for determination of tritium depth profiles in metallic samples
}

\section{JET Contributors}

$2019-10$

JET Contributors , Kotschenreuther , M , Ahlgren , T , Aho-Mantila , L , Airila , M , Björkas , C , Heinola , K, Lahtinen , A , Nordlund , K, Safi , E , Pehkonen, S-P , Pajuste , E \& Jarvinen , A 2019 , ' Novel method for determination of tritium depth profiles in metallic samples ', Nuclear Fusion , vol. 59 , no. 10 , 106006 . https://doi.org/10.1088/1741-4326/ab3056

http://hdl.handle.net/10138/324314

https://doi.org/10.1088/1741-4326/ab3056

acceptedVersion

Downloaded from Helda, University of Helsinki institutional repository.

This is an electronic reprint of the original article.

This reprint may differ from the original in pagination and typographic detail.

Please cite the original version. 


\title{
NOVEL METHOD FOR DETERMINATION OF TRITIUM DEPTH PROFILES IN METALLIC SAMPLES
}

\author{
Elina Pajuste ${ }^{1,2}$, Gunta Kizane ${ }^{1}$, Liga Avotina ${ }^{1}$, Anete Stine-Teimane ${ }^{1,2}$, Andris \\ Lescinskis $^{1}$, Karlis Vonda ${ }^{1,2}$ and JET contributors ${ }^{* 3}$ \\ ${ }^{1}$ Institute of Chemical Physics, University of Latvia, Riga, Latvia \\ ${ }^{2}$ Faculty of Chemistry, University of Latvia, Riga, Latvia \\ ${ }^{3}$ EUROfusion Consortium, JET, Culham Science Centre, Abingdon, OX14 3DB, UK \\ E-mail: elina.pajuste@lu.lv
}

Received xxxxxx

Accepted for publication $\mathrm{xxxxx}$

Published xxxxxx

\begin{abstract}
Tritium accumulation in the fusion reactor materials is considered as a serious radiological issue, therefore efforts are concentrated on the development of radiometric techniques. A novel method, based on gradual dissolution, for the determination of the total tritium content and its depth profiles in metallic samples is demonstrated. The method allows for measuring tritium in metallic samples after their exposure to hydrogen and tritium mixture, tritium containing plasma or after irradiation with neutrons resulting in the tritium formation. In the method, successive layers of metal are removed using appropriate etching agent in the controlled regime and amount of evolved gases measured by the means of chromatography (gas composition and release rate) and proportional gas flow detector (tritium). Results on $\mathrm{T}$ profiles in neutron irradiated, plasma exposed and gas loaded beryllium are reported.
\end{abstract}

Keywords: tritium, depth profile, fusion, first wall, breeding blanket, beryllium

\section{Introduction}

Tritium retention in the fusion reactor materials is a key issue in terms of both tritium (T) breeding self-sufficiency and safety of a fusion plant. In the International Thermonuclear Experimental Reactor (ITER), limits of in-vessel tritiuminventory are an integral part of the ITER safety case and are fixed at $1 \mathrm{~kg}$ [1]. Only $2 \%$ of injected tritium and deuterium will be "burnt" in fusion reactions, while the rest is to be removed back to the tritium plant. However, a certain fraction will remain in a reactor thus contaminating vacuum vessel components, both their surfaces and - through the permeation - also bulk of materials [2]. Materials under the risk of contamination with tritium are those used for construction of internal components of the ITER machine - the blanket system and the divertor [3]. The first wall of the blanket will be covered with metallic beryllium (Be). Divertor, the component to withstand the highest heat loads, will be made of metallic tungsten (W) [4].

Tritium gas present in the vessel can accumulate in plasmafacing components (PFC) as a result of co-deposition with eroded materials and, by physical diffusion, into the bulk. Codeposited tritium is expected to be retained in the near-surface region of PFC, however tritium as a hydrogen isotope is very mobile due to its small size and might diffuse much deeper into the bulk. Such parameters as solubility, trapping energies and diffusivity plays significant role in the estimation of the diffusion depth. Theoretical model of tritium trapping on the imperfections of the lattice, such as vacancies, grain boundaries, etc. has been described [5,6]. Some properties might be extrapolated from available data for protium or

${ }^{*}$ See author list in the paper, X. Litaudon et al., Nucl. Fusion, 57 (2017) 102001 
deuterium, however, isotopic effects must be taken into account [7]. Comprehensive overview of the experimental data on hydrogen solubility, diffusivity and permeation has been provided by R. A. Causey in 2012 [8].

Beryllium choice is based on its low-Z, good thermal conductivity $(210 \mathrm{~W} / \mathrm{mK})$ and high affinity towards oxygen i.e. gettering. Be has been tested as PFC material in the currently largest tokamak - Joint European Torus JET [9] (first introduction in 1989, since 2012 - ITER-Like-Wall (ILW) project [10]) and also in smaller early period tokamaks such as UNITOR and ISX-B [11].

Tungsten is chosen due to its high thermal stress resistance, thermal conductivity $(175 \mathrm{~W} / \mathrm{mK})$, low erosion by light projectiles and low hydrogen retention[12]. Currently it is being tested in JET-ILW.

Fusion power reactors will have to breed tritium by using the reaction between lithium- 6 and neutrons to provide fuel for the fusion process, in order to become self-sufficient in this scarce commodity: beryllium will be also a key component in this breeding process as an extremely effective neutron multiplier. Different types of tritium breeding modules (TBM) are planned to be tested in ITER. European Union proposes to test two concepts of helium-cooled tritium breeding blanket modules. In one of them - "Helium-Cooled Pebble Bed (HCPB) blanket", lithium ceramic pebbles are used as a T breeder and metallic Be pebbles as a neutron multiplier [13]. Beryllium swelling, embrittlement and hardening as a result of the neutron irradiation are important issues regarding its mechanical performance, whereas tritium production and its inventory as a result of neutron-induced transmutations [14] are significant safety issue. In the frame of the European Power Plant Conceptual Study, the peak integral gas production in beryllium, at the End-Of-Life of HCPB modules (40 $000 \mathrm{~h}$ operation), has been assessed at the level of 25700 appm He and 640 appm T, taking into account in-pile tritium decay. The global T production in the whole blanket (390 tons of $\mathrm{Be}$ ) is $23.8 \mathrm{~kg}$ [15]. At the reactor operational temperature a large fraction of tritium remains in the bulk of pebbles and in case of accidental temperature excursions this inventory of radioactive gas can be released in a short time thus putting under the risk employees of the fusion plant.

Tritium behaviour prediction and estimation of its overall retention in fusion devices is of high importance. Assessment of tritium depth profiles in the exposed materials would give crucial information for the optimal detritiation (removal of tritium from the materials in order to achieve lower radioactive waste level [16]) techniques selection. In this study, a novel method for determining both depth profiles and the total amount of tritium in metallic samples is demonstrated and discussed.

\section{Materials}

The method based on gradual material dissolution and tritium radiometry has been applied to a variety of Be-based materials: plasma exposed, neutron irradiated and loaded with tritium/hydrogen gas mixture. They are described below. For tungsten materials method has been developed and described, but not demonstrated on tritium containing material yet.

\subsection{Plasma-facing materials from JET tokamak}

ITER-Like-Wall (ILW) project has been carried out at Joint European Torus JET to test plasma facing materials relevant to International Thermonuclear Experimental Reactor - ITER. During regular shutdowns material samples are retrieved for off-situ analysis. The plasma-facing wall in the main chamber of JET is made of bulk beryllium tiles, whereas for the divertor bulk tungsten and tungsten-coated carbon fibre composite tiles are used [17].

During the first two ILW campaigns, ILW-1 and ILW-2, only stable hydrogen isotopes have been introduced in the vacuum vessel of JET. However, there are several possible sources of tritium in the beryllium wall materials: in-vessel tritium inventory remaining from previous D-T campaigns, energetic tritium ion production as a result of $\mathrm{D}-\mathrm{D}$ reaction and tritium production in neutron-induced transmutation of beryllium. This transmutation-related source of $\mathrm{T}$ will play significant role in future fusion devices but cannot be considered as major one in JET. It must be emphasized that the overall neutron yield in ILW-1 and ILW-2 was very low: $\sim 5 \cdot 10^{19}$ in total.

There have been three campaigns in JET when tritium was used: Preliminary Tritium Experiment (PTE) in 1991 [18] the first Deuterium-Tritium Experiment (DTE1) in 1997 [19, 20] and the Trace Tritium Experiment (TTE) in 2003 [21]. In total $420 \mathrm{mg}$ of tritium has been introduced $(5 \mathrm{mg}-\mathrm{PTE}, 35 \mathrm{~g}-$ DTE1 and $380 \mathrm{mg}$ - TTE) [22]. Tritium can be produced in vacuum vessel also as a product of the $\mathrm{D}-\mathrm{D}$ fusion reaction (1)

$$
{ }_{1}^{2} \mathrm{H}(\mathrm{H})+{ }_{1}^{2} \mathrm{H}(\mathrm{D}) \rightarrow{ }_{1}^{3} \mathrm{H}(\mathrm{T})+{ }_{1}^{1} \mathrm{H}(\mathrm{H})+4.03 \mathrm{MeV}
$$

During the shutdowns in 2012 (ILW1) and 2014 (ILW2), selected beryllium tiles were removed from the following positions of the vacuum vessel - inner wall (Inner Wall Guarding Limiter - IWGL), outer wall (Wide Poloidal Limiter - WPL) and upper vessel part (Dump Plate - DP). Samples of approximately $1.2 \times 1.2 \times 1.0 \mathrm{~cm}^{3}$ cut out of tiles (as described in [23]) were used in the present study. These samples were further cut into two parts in order to perform tritium depth profiling and desorption experiments.

Specific tungsten samples for which method is developed are from JET divertor and has been exposed in vacuum vessel during ILW-1 campaign. Etching system geometry has been adapted for the received samples of approximately $0.5 \times 1.2 \times 1.0 \mathrm{~cm}^{3}$ that has been cut out of divertor tiles.

\subsection{Neutron-irradiated beryllium pebbles}

Neutron irradiation is one of the main obstacles complicating the material choice due to the problems it causes; e.g., neutron-induced transmutations (long-term activation, tritium inventory in $\mathrm{Be}$ materials) and structure degradation (brittleness, swelling etc). A wide variety of neutron 
irradiation projects for breeding blanket materials have been undertaken at the High Flux Reactor (HFR), located in Petten, the Netherlands. Post irradiation examination of Be samples from one of them, HIDOBE-01(HIgh DOse irradiation of BEryllium) [24], have been analysed by the proposed method. In the HIDOBE-01 experiment, beryllium pebbles were irradiated at four different target temperatures $\left(425{ }^{\circ} \mathrm{C}\right.$, $525^{\circ} \mathrm{C}, 650^{\circ} \mathrm{C}$ and $750{ }^{\circ} \mathrm{C}$ ) up to the dose corresponding to 3000 appm He production in beryllium[25].

\subsection{Tritium loaded beryllium pebbles}

In order to estimate and compare $\mathrm{T}$ behaviour in different samples prior to irradiation has been introduced by the Karlsruhe Institute of Technology (KIT). This is loading with tritium gas at elevated temperatures which could be considered as alternative way to saturate Be pebbles with $\mathrm{T}$. Tritium depth profiles in loaded pebbles have been measured by the method used in this work. Two types of pebbles produced by different methods were compared - produced by Rotating Electrode Method REM (NGK, Japan) and -Fluoride Reduction Method FRM (Materion Brush, USA). Samples were loaded at KIT under exposure to the hydrogen and tritium mixture $\left({ }^{1} \mathrm{H}_{2}+500\right.$ appm $\left.{ }^{3} \mathrm{H}_{2}\right)$ for 15 hours at the temperature of $600{ }^{\circ} \mathrm{C}$ and $850{ }^{\circ} \mathrm{C}, 4$ bar pressure [26, 27].

\section{Method for determination of tritium depth profiles}

Method is based on the simultaneous etching of the metal surface and measurements of the released tritium. Beryllium can be etched chemically in acid solutions, whereas tungsten must be etched electrochemically due to its low reactivity with chemical etchants or due to the formation of complex mixtures of the reaction products. Experimental setup for dissolution experiments is shown in Figure 1. and electrochemical etching in Figure 2.

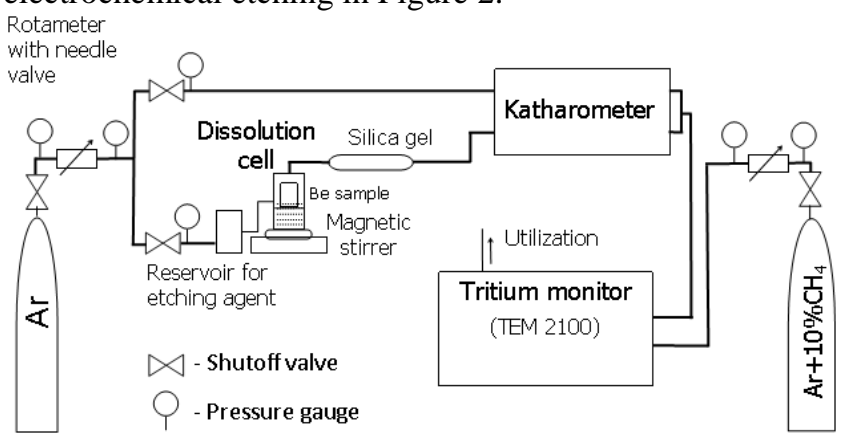

Figure 1 Dissolution setup for Be

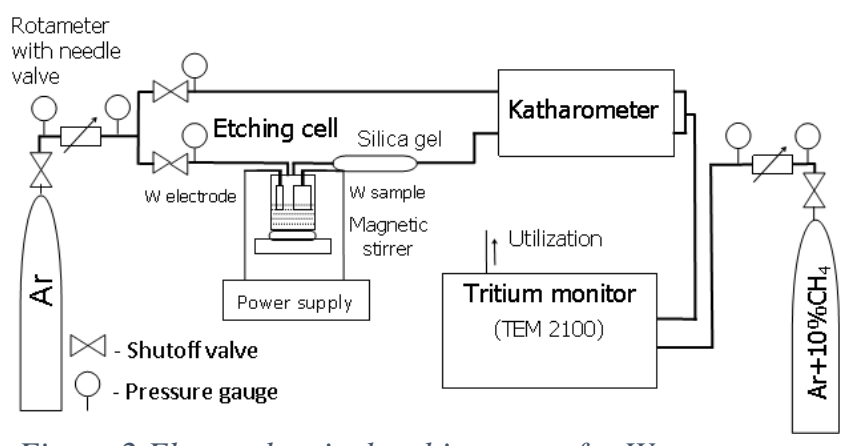

Figure 2 Electrochemical etching setup for $W$

Surface layers of Be are sequentially removed using 1 $\mathrm{mol} / \mathrm{L}$ sulphuric acid, whereas layer of tungsten electrochemically in $30 \% \mathrm{KOH}$ solution. Amount of evolved hydrogen (denoted as ' $\mathrm{H}$ ') and released tritium (denoted as ' $\mathrm{T}$ ') are simultaneously measured. Following processes occur during dissolution $\mathrm{Be}$ and $\mathrm{W}$ :

$$
\begin{aligned}
& \mathrm{Be}+2 \mathrm{H}^{+} \rightarrow \mathrm{Be}^{2+}+2 \mathrm{H}^{0} \\
& \mathrm{~W}+2 \mathrm{OH}^{-}+2 \mathrm{H}_{2} \mathrm{O} \rightarrow \mathrm{WO}_{4}^{2-}+6 \mathrm{H}^{0} \\
& \mathrm{H}^{0}+\mathrm{H}^{0} \rightarrow \mathrm{H}_{2 \text { (gas ph.) }} \\
& \mathrm{H}^{0}+\mathrm{T}^{0}{ }_{\text {(solid phase) }} \rightarrow \mathrm{HT} \text { (gas ph.) } \\
& \mathrm{T}_{2 \text { (solid ph.) }} \rightarrow \mathrm{T}_{2 \text { (gas ph.) }} \\
& \mathrm{T}_{(\text {solid ph.) }}^{+} \rightarrow \mathrm{T}^{+} \text {(liquid ph.) }
\end{aligned}
$$

where, ' $\mathrm{T}^{0}$ (solid phase) 'refers to tritium atoms as interstitials in the bulk of solid metal, ' $\mathrm{T}_{2 \text { (solid ph.) }}$ - molecular tritium trapped in the volume of the material, ' $\mathrm{T}^{+}$(solid ph.)' - tritium chemically bonded with the impurities such as oxygen, whereas ' $\mathrm{T}_{2}$ (gas ph.) '- molecular tritium released in the flow of the purge gas and ' $\mathrm{T}^{+}$(liquid ph.)' - tritium remaining in the acid solution as a part of the $\mathrm{HTO}^{+}$ion or in alkaline solutions as $\mathrm{OT}^{-}$.

Molecular $\mathrm{T}_{2}$ and atomic $\mathrm{T}^{0}$ (interstitial) tritium of the activities $\mathrm{A}_{\mathrm{T} 2}$ and $\mathrm{A}_{\mathrm{T} 0}$ respectively, present in a sample transfer as $\mathrm{T}_{2}+\mathrm{HT}$ into a flow of carrier gas, where the tritium activity was measured by proportional counter with an operating volume of $300 \mathrm{~cm}^{3}$ and a tritium monitor TEM 2102A (Mab Solutions $\mathrm{GmbH}$ ).

$$
A_{T, \text { gas.ph }}=A_{T_{2}}+A_{T^{0}}
$$

Chemically bonded tritium (depicted as ' $\mathrm{T}^{+}$' in the processes schemes) localized in a sample layer remains in the solution and the tritium activity $\mathrm{A}_{\mathrm{T}}$, liquid ph. was measured with liquid scintillation method. Solution containing tritium was distilled and 5 or $1 \mathrm{~mL}(+4 \mathrm{~mL}$ deionized water) aliquot mixed with $15 \mathrm{~mL}$ of Ultima Gold scintillation cocktail and analysed for total tritium with a TRi-Carb 2910TR counter (PerkinElmer, Inc). The amount of $\mathrm{T}$ atoms can be calculated using the tritium decay constant $\lambda=1,7810^{-9} \mathrm{~s}^{-1}[5]$

$$
N_{T}=\frac{A_{T}}{\lambda}
$$

Calculations of the $\mathrm{T}$ distribution in the bulk are based on the controlled dissolution/electrochemical etching process. In case of beryllium, one hydrogen molecule corresponds to one beryllium (Eq. 1 and 2) atom and the dissolution rate of 
Be, hence the thickness of the dissolved layer can be calculated from the number of hydrogen molecules evolved.

The amount of hydrogen amount was measured by means of gas chromatography using thermal conductivity detector (TCD). By this method all hydrogen isotopes are measured as one signal, however tritium and deuterium concentrations are very low in comparison to the amount of protium evolved during the beryllium dissolution process. Calculation of the dissolved Be layer at the moment $t$ depends of the shape of the sample and expected tritium distribution. In the pebbles it can be assumed that its depth is quite uniform on the entire surface, whereas for samples from the vacuum vessel - most of the tritium is expected to be accumulated in the plasma-facing surface layer.

\subsection{Flat surfaces - plasma exposed beryllium tiles}

Dissolved beryllium layer $L_{t}$ at the moment $t$ can be calculated from the number hydrogen molecules evolved, $N_{H 2, t}$.

$$
L_{t}=\frac{N_{H_{2}, t} \cdot M_{B e}}{N_{A} \cdot \rho_{B e} \cdot S_{B e, d i s}}
$$

where $M_{B e^{-}}$beryllium atomic mass $(9.012 \mathrm{u}), N_{A}$-Avogadro constant $\left(6.022 \cdot 10^{23} \mathrm{~mol}^{-1}\right), \rho_{B e^{-}}$beryllium theoretical density $\left(1.85 \mathrm{~g} / \mathrm{cm}^{3}\right)$ and $\mathrm{S}_{\mathrm{Be}, \text { dis }}\left(\mathrm{cm}^{2}\right)$ - surface area of the beryllium sample being etched by the acid.

\subsection{Spherical samples - beryllium pebbles}

In the case of spherical sample, it can be assumed that its surface has been exposed to tritium gas or/and neutron irradiation similarly. Therefore, sample is fully immersed in the etching agent to ensure simultaneous beryllium dissolution from all of its surface.

If dissolution process of the beryllium pebble starts at $\mathrm{t}=\mathrm{t}_{0}$ and radius of the pebble in this moment is $\mathrm{r}_{0}$, it could be calculated as follows:

$$
r_{0}=\sqrt[3]{\frac{3 m_{0}}{4 \pi \rho_{B e}}}
$$

where, $r_{0}$ - initial radius of the pebble, $\mathrm{cm}$; $m_{0}$ - mass of the pebble, $\mathrm{g}$;

$\rho_{B e}-$ beryllium density, $\mathrm{g} / \mathrm{cm}^{3}$. follows:

Radius of the pebble in the moment $t$ is calculated as

$$
r_{t}=\sqrt[3]{\frac{3\left(m_{0}-\Delta m_{t}\right)}{4 \pi \rho_{B e}}}
$$

where $\Delta \mathrm{m}_{\mathrm{t}}$ is a mass of dissolved Be at the moment $t$ and it can be calculated from the amount of released hydrogen (tritium gas contribution is negligible and, therefore, is not taken into account).

$$
\Delta m_{t}=\frac{N_{H_{2}}}{N_{A} \cdot M_{B e}}
$$

The resolution of this method is determined by sample properties (porosity, grain size), geometry of the setup (volumes of the dissolution cell, the column filled with silica gel and tritium detector), the flow rate of the argon carrier gas and the rate of dissolution of the beryllium sample in $1 \mathrm{~mol} / \mathrm{L}$ sulphuric acid. Resolution is limited by the initial surface roughness of the sample and non-uniform dissolution of the material. After the removal of samples from the solution microscopy studies of acid-exposed surfaces were performed. This analysis revealed surface features with the maximum roughness of up to $10 \mu \mathrm{m}$. Therefore, the resolution was assumed to be $\sim 10 \mu \mathrm{m}$. Depth profile plots are constructed from the tritium and hydrogen measurement data and they are precise in the case of initially smooth surface of the sample.

\section{Results}

\subsection{Plasma facing materials}

Results obtained by the proposed method have showed that $95 \%$ of tritium is accumulated in the first $30-100 \mu \mathrm{m}$ from the plasma-facing surface of the Be tiles used in JET ILW [28]. An example of the T depth profile in the beryllium tile is given in Figure 3, where the concentration is calculated per square centimetre of the plasma-facing surface. That particular sample was cut from the tile retrieved from JET after the first ILW campaign in 2012.

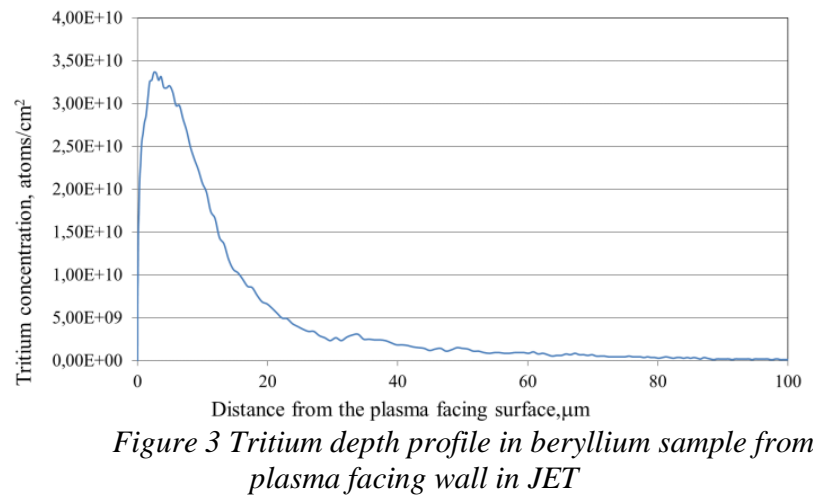

Prior to the dissolution SEM studies were performed to determine the surface structure because the resolution of depth profiling is dependent on the initial surface roughness. The method gives also information about the total tritium content in the sample. Therefore, it is applied for specimens with highly damaged surface. Detailed data on tritium concentration in beryllium tiles from different locations in JET after ILW-1 and ILW-2 campaigns are describe in [29].

\subsection{Neutron irradiated materials}

It can be assumed that the distribution of transmutation products in the bulk of small objects (like pebbles) is statistically uniform. Therefore, $\mathrm{T}$ depth profiles in the neutron- irradiated pebbles can provide information on the tritium release/retention mechanisms. The measurements of the neutron-irradiated pebbles have shown uniform distribution in the bulk of the pebble with decreased concentration towards the pebble surfaces. Some higher concentration peaks in individual samples could be also 
observed. An example of the depth profile is given in Figure 4.

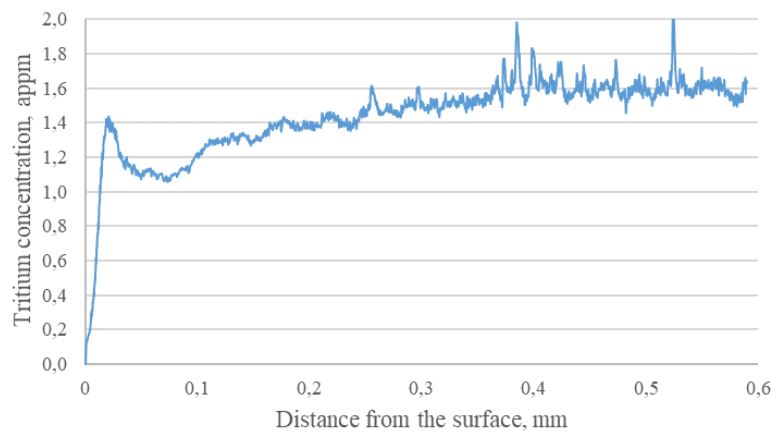

Figure 4 Tritium depth profile in neutron irradiated $1 \mathrm{~mm}$ beryllium pebble from experiment HIDOBEOI

Low concentration near the surface indicates tritium desorption during the sample storage in ambient atmosphere, whereas peaks can be associated with tritium accumulation in the pores that have also been found during the structural analysis [30]. Large pores/voids are generated during the cooling phase of the fabrication process. Developers of the fabrication method has claimed that these pores are specially developed to prevent beryllium swelling and failure when irradiated with neutrons as helium produced in the nuclear reactions is stored in this void instead of beryllium lattice[31]. However, it must be emphasized that it also acts as a trap for tritium, thus preventing its release during the reactor operation. Tritium accumulation in these voids has been also demonstrated by this research.

\subsection{Tritium loaded materials}

Results obtained by the proposed method revealed that after the gas loading experiment, tritium its distribution in samples is not uniform. Higher T concentration of tritium is detected in the 100-200 $\mu \mathrm{m}$ thick near-surface layer of the pebbles. Smaller peaks of tritium might be related to the near surface closed micro-cracks formed during thermal treatment of the pebble, that are revealed during dissolution process releasing accumulated tritium. Results for pebbles produced by REM and FRM methods loaded at $850{ }^{\circ} \mathrm{C}$ for 15 hours is shown in Figure 5.

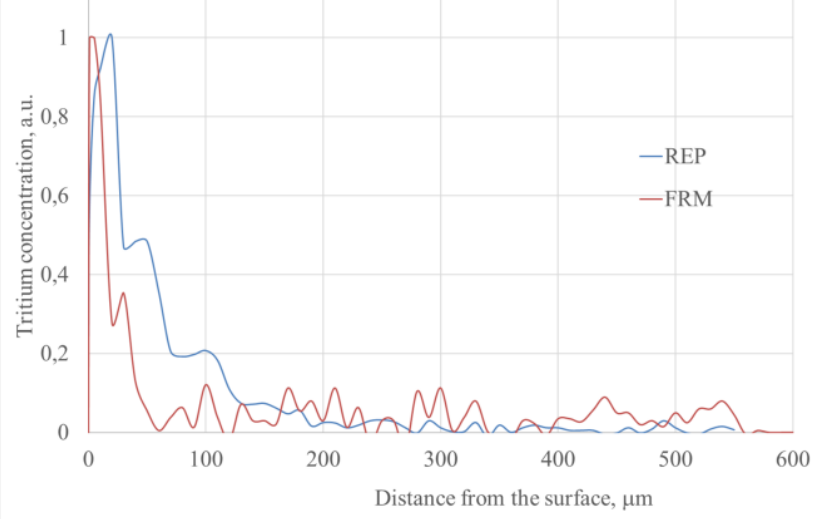

Figure 5 Tritium depth profile in beryllium pebbles loaded with tritium/hydrogen gas mixture at $850 \mathrm{oC}$, tritium concentration is normalized to the maximum concentration for each sample for better comparison

Since method provides also information on total tritium amount in the sample it was possible to measure also amount of tritium remained in the pebbles after loading process. Method revealed that both penetration depth and total amount highly depends on the type of the pebble. After loading at $850 \mathrm{oC}$ tritium concentration in pebbles produced by REM varies from 0.7 to $2.6 \mathrm{MBq} / \mathrm{g}$ and penetration depth for some samples reached up to $400 \mu \mathrm{m}$ whereas for FRM pebbles this range is narrower: 0.5 to $0.7 \mathrm{MBq} / \mathrm{g}$ and penetration depth do not exceed $100 \mu \mathrm{m}$.

\section{Discussion}

\subsection{Tritium depth profile for different tritium accumulation mechanisms}

Results of three different samples has been reported in this paper: plasma facing materials, neutron irradiated and tritium/hydrogen gas loaded. These samples represent also three different tritium accumulation mechanisms: tritium co-deposition with eroded material and further diffusion into the bulk and energetic tritium ion implantation (PFM), tritium production as a result of neutron induced transmutation of the studied material and tritium absorption followed by diffusion from the tritium containing gas. All of these processes will take place in the fusion reactor and it is important to assess the critical tritium retention root for further prediction of its inventory in reactor materials in the future devices.

From the data presented above it is obvious that neutron induced transmutations causes tritium accumulation throughout all the bulk of the material, whereas codeposion/ion implantation and absorbtion affects only near surface layers of hundred to few hundred micrometers. In the real energy producing fusion power plant neutron yield will be high and in case of beryllium based plasma facing material tritium production as a result of neutron transmutation could be considered as an operation safety and nuclear waste issue. Most of the detritiatio methods for tritium removal for the retrieved materials before their disposal are based of the surface heating, however, if there is tritium accumulation in all the bulk of the material temperature close to the melting temperature must be used.

\subsection{Comparison of the proposed method with alternative methods for tritium depth profiling.}

5.1. $\beta$-ray induced X-ray spectrometry[32] 
This method has high resolution (nm), however it is sensitive only to near surface tritium: $3 \mu \mathrm{m}$ and $0.3 \mu \mathrm{m}$ for $\mathrm{Be}$ and $\mathrm{W}$, respectively. $\beta$-ray induced X-ray spectrometry can be used also for tritium concentration mapping on the surface. No data on total tritium amount in the whole sample.

5.2. Glow discharge optical emission spectroscopy (GD-OES) Method is based on simultaneous surface etching with $\mathrm{Ar}$ plasma and optical stimulation of the eroded material. If to compare with method described above broader depth range can be achieved, however, by now method has been demonstrated on stable hydrogen isotopes $\mathrm{H}$ and $\mathrm{D}$, only [33]. Method can also be used for surface mapping, however there is a risks that tritium in other parts of the sample is released due to elevated temperature. No data on total tritium amount in the whole sample.

5.3. Imaging plate technique

Method is based on tritium beta radiation interaction with radiosensitive material. Due to small beta radiation range in solid samples method gives information only on the near surface tritium. In [34] application of the method for depth profile is also demonstrated. In order to obtain depth profile cross-section of the sample is obtained and imagine plate reading performed on the cut surface. Drawback of this method is possible loss tritium in the cut surface due to local heating (especially for hard materials such as Be and W).

Main advantage of the proposed method in comparison with alternatives is total tritium amount data and unlimited depth of measurement, whereas disadvantage is its low resolution.

\section{Summary}

The method presented in this study is a tool for the quantitative determination of tritium depth profile/bulk distribution in beryllium materials of different type and geometry. Successful application of the proposed method has been demonstrated for neutron-irradiated, plasma-exposed and tritium gas-loaded beryllium. Results obtained demonstrate the possibility to use tritium loading method for estimation of tritium behavior in different types of beryllium materials as tritium is also diffusing into the bulk of the material.

Resolution of the method is limited by the roughness/tritium penetration depth ratio. Therefore, surface analysis prior to the measurement is necessary. Tritium depth profile can be measured for other materials if appropriate etching agent/technique is applied. Currently, a technique based on electrochemical etching method is being developed for tungsten specimens.

\section{Acknowledgements}

This work has been carried out within the framework of the EUROfusion Consortium and has received funding from the Euratom research and training programme 2014-2018 under grant agreement No 633053. The views and opinions expressed herein do not necessarily reflect those of the European Commission.

\section{References}

[1] Shimada, M., R.A. Pitts, S. Ciattaglia, et al., 2013, Journal of Nuclear Materials. 438: S996.

[2] Taylor, N., B. Merrill, L. Cadwallader, et al., 2017, Nuclear Fusion. 57(9): 092003.

[3] Merola, M., F. Escourbiac, R. Raffray, et al., 2014, Fusion Engineering and Design. 89(7): 890.

[4] Lorenzetto, P., J. Andrade, S. Banetta, et al., 2018, Fusion Engineering and Design.

[5] Ganchenkova, M.G., V.A. Borodin, and R.M. Nieminen, 2009, Physical Review B. 79(13): 134101.

[6] Longhurst, G.R., R.A. Anderl, T.J. Dolan, et al., 1995, Fusion Technology. 28(3P2): 1217.

[7] Kaur, R. and S. Prakash, 1982, Journal of Physics F: Metal Physics. 12(7): 1383.

[8] Causey, R.A., R.A. Karnesky, and C. San Marchi, 4.16 - Tritium Barriers and Tritium Diffusion in Fusion Reactors, in Comprehensive Nuclear Materials, R.J.M. Konings, Editor. 2012, Elsevier: Oxford. p. 511.

[9] Rebut, P.-H., 2018, The European Physical Journal H. 43(4): 459.

[10] Horton, L., 2015, Fusion Engineering and Design. 96-97: 28 .

[11] Federici, G., V. Barabash, R. Doerner, et al., Beryllium as a Plasma Facing Material for NearTerm Fusion Devices, in Reference Module in Materials Science and Materials Engineering. 2016, Elsevier.

[12] Pintsuk, G., 4.17 - Tungsten as a Plasma-Facing Material, in Comprehensive Nuclear Materials, R.J.M. Konings, Editor. 2012, Elsevier: Oxford. p. 551.

[13] Hernández, F., P. Pereslavtsev, Q. Kang, et al., 2017, Fusion Engineering and Design. 124: 882.

[14] Evans, J.E., REACTION PRODUCTS IN HIGH nvt IRRADIATED BERYLLIUM. 1956, ; Phillips Petroleum Co. Atomic Energy Div., Idaho Falls, Idaho. p. Medium: ED; Size: Pages: 11.

[15] Rabaglino, E., C. Ronchi, and A. Cardella, 2003, Fusion Engineering and Design. 69(1): 455.

[16] Decanis, C., M. Kresina, and D. Canas, 2018, Fusion Engineering and Design. 136: 276.

[17] Horton, L., 2013, Fusion Engineering and Design. 88(6): 434.

[18] Team, J.E.T., 1992, Nuclear Fusion. 32(2): 187.

[19] Jacquinot, J., V.P. Bhatnagar, J.G. Cordey, et al., 1999, Nuclear Fusion. 39(2): 235.

[20] Keilhacker, M., A. Gibson, C. Gormezano, et al., 1999, Nuclear Fusion. 39(2): 209.

[21] Zastrow, K.D., J.M. Adams, B. Yu, et al., 2004, Plasma Physics and Controlled Fusion. 46(12B): B255.

[22] Stork, D., B. Yu, P. Belo, et al., 2005, Nuclear Fusion. 45(10): S181.

[23] Widdowson, A., A. Baron-Wiechec, P. Batistoni, et al., 2016, Physica Scripta. 2016(T167): 014057. 
[24] van Til, S., J.B.J. Hegeman, H.L. Cobussen, et al., 2011, Fusion Engineering and Design. 86(9): 2258.

[25] Fedorov, A.V., S. van Til, M.P. Stijkel, et al., 2016, Fusion Engineering and Design. 102: 74.

[26] Chakin, V., A. Moeslang, P. Kurinskiy, et al., 2011, Fusion Engineering and Design. 86(9-11): 2338.

[27] Chakin, V., R. Rolli, A. Moeslang, et al., 2016, Fusion Engineering and Design. 107: 75.

[28] Pajuste, E., G. Kizane, A. Vitins, et al., 2017, Nuclear Materials and Energy. 12(Supplement C): 642.

[29] Pajuste, E., G. Kizane, I. Igaune, et al., 2019, Nuclear Materials and Energy. 19: 131.

[30] Pajuste, E., G. Kizane, L. Avotina, et al., 2015, Journal of Nuclear Materials. 465: 293.

[31] Ishitsuka, E., H. Kawamura, and N. Sakamoto, Process for preparing metallic beryllium pebbles, U.S. Patent, Editor. 1999, NGK Insulators Ltd, Japan Atomic Energy Research Institute

[32] Hatano, Y., K. Yumizuru, S. Koivuranta, et al., 2017, Physica Scripta. 2017(T170): 014014.

[33] Taylor, C.N. and M. Shimada, 2017, AIP Advances. 7(5): 055305.

[34] Otsuka, T. and T. Tanabe, 2017, MATERIALS TRANSACTIONS. 58(10): 1364. 